\title{
Vertical structure variability in the equatorial Pacific before and after the Pacific climate shift of the 1970s
}

\author{
Byung-Kwon Moon, ${ }^{1}$ Sang-Wook Yeh, ${ }^{2}$ Boris Dewitte, ${ }^{3}$ Jong-Ghap Jhun, ${ }^{1}$ In-Sik Kang, ${ }^{1}$ \\ and Ben P. Kirtman ${ }^{2,4}$ \\ Received 13 October 2003; accepted 9 January 2004; published 7 February 2004.
}

[1] Oceanic baroclinic modes in the equatorial Pacific are estimated using results from the SODA system. Our result suggests that the vertical stratification increases at the upper levels after the late 1970s due to changes in the vertical temperature structure. After the late 1970s, the variability of the higher-order baroclinic mode contributions to current anomalies and surface pressure significantly increases in the central equatorial Pacific. This is associated with an increase of the dominant period of the ENSO variability. Simple coupled model experiments indicate that when atmospheric forcing projects more onto the higher baroclinic modes according to the results of the SODA decomposition, the amplitude and dominant period of ENSO increase similarly to what is observed at the Pacific decadal shift. Our results support that the changes in the behavior of ENSO after the late 1970s are associated with oceanic vertical structural changes in temperature that tend to increase the contribution of higher-order baroclinic modes. INDEX TERMS: 3339 Meteorology and Atmospheric Dynamics: Ocean/atmosphere interactions (0312, 4504); 3374 Meteorology and Atmospheric Dynamics: Tropical meteorology; 4522 Oceanography: Physical: El Nino; 4215 Oceanography: General: Climate and interannual variability (3309); 4231 Oceanography: General: Equatorial oceanography. Citation: Moon, B.-K., S.-W. Yeh, B. Dewitte, J.-G. Jhun, I.-S. Kang, and B. P. Kirtman (2004), Vertical structure variability in the equatorial Pacific before and after the Pacific climate shift of the 1970s, Geophys. Res. Lett., 31, L03203, doi:10.1029/2003GL018829.

\section{Introduction}

[2] The causes of ENSO decadal variability (EDV) are currently not known. In one view, the EDV is generated at midlatitudes where the North Pacific decadal variability is subsequently communicated to the tropics by atmospheric or oceanic teleconnections [Zhang et al., 1998]. In another, it results from tropical processes alone [Knutson and Manabe, 1998]. Without fully excluding the influence from the extratropics, the latter hypothesis is seductive considering that there are increasing evidences that the vertical structure of the low frequency variability found in the tropical Pacific Ocean cannot be reduced to a single mode [Kessler and

\footnotetext{
${ }^{1}$ School of Earth and Environmental Sciences, Seoul National University, Seoul, Korea.

${ }^{2}$ Center for Ocean-Land-Atmosphere Studies, Calverton, Maryland, USA.

${ }^{3}$ Laboratoire d'Etude en Géophysique et Océanographie Spatiale, IRD, New Calédonia, France.

${ }^{4}$ George Mason University, Fairfax, Virginia, USA.
}

McCreary, 1993; Shu and Clarke, 2002]. The higher-order baroclinic mode can set up a slower variability through the complex coupled instabilities [Dewitte, 2000; Yeh et al., 2001]. Although the characteristics of the vertical modes vary in the tropical Pacific with time [cf. Dewitte et al., 1999], the magnitude and pattern of these variations at interannual and decadal timescales remain unknown.

[3] In this study, we use the results from the Simple Ocean Data Assimilation (SODA) system [Carton et al., 2000] to investigate the change in the baroclinic mode contribution during the period of 1950-1997. A special focus is on the climate shift in the tropical Pacific Ocean around the mid-1970s. The dominant ENSO oscillation period increased from 2-3 years during 1960-1975 to 4-6 years after the late 1970s [Wang and Wang, 1996]. The amplitude of ENSO also tends to increase. Our motivation is to investigate if such changes can be associated with the variability of the vertical baroclinic modes before and after the late 1970s.

\section{Data}

[4] Monthly upper ocean data, which includes temperature, salinity and currents, for the period of 1950-1997 were obtained from the SODA system. SODA uses an ocean model based on GFDL MOM2 physics [Pacanowski et al., 1993]. The reader is invited to refer to Carton et al. [2000] for detail description of the SODA system.

\section{Analysis and Results}

[5] We first show the vertical profile of mean buoyancy frequency $N^{2}(z)$ for the central Pacific $\left(0^{\circ} \mathrm{N}, 160^{\circ} \mathrm{E}-220^{\circ} \mathrm{E}\right)$ before and after the late 1970s (Figure 1a). Here, $N$ is the Brunt-Väisälä frequency. The vertical stratification substantially increases after the late 1970 s at upper levels $(\sim 150 \mathrm{~m})$ indicating a stable oceanic condition. In order to estimate the contribution of vertical structural changes in the temperature and salinity responsible for an increase of $N^{2}(z)$, we calculate $N^{2}(z)$ using a climatological (1960-1997) temperature and salinity, respectively. Figure $1 \mathrm{~b}(\mathrm{c})$ is the same as in Figure 1a except for the climatological salinity (temperature). The change of vertical salinity structure before and after the late 1970s does not make a difference in the profiles of $N^{2}(z)$ (Figure 1c). This result clearly shows that changes in $N^{2}(z)$ (Figure 1a) are preferentially due to the change of vertical temperature structure. Indeed, the mean longitude-temperature section along the equator between the two epochs (Figure 1d) shows temperature structures with sign alternating in the vertical, indicative of increased vertical stratification after the late 1970s. 

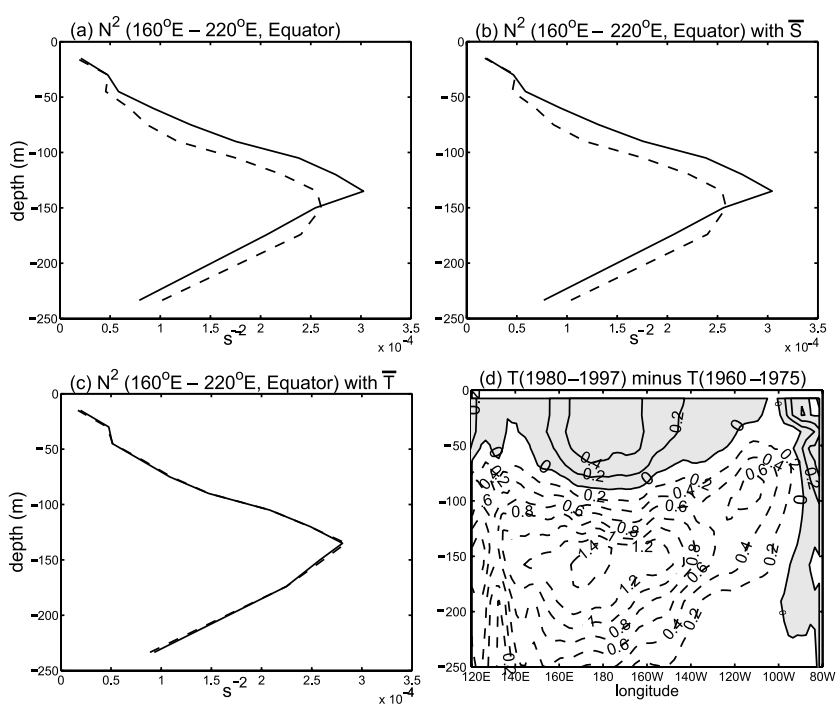

Figure 1. The vertical profiles of the Brunt-Väisälä frequency, $N^{2}(z)$ for the period of 1960-1975 (dashed) and 1980-1997 (solid) (a). (b) and (c) are the same as in (a) except for the climatological (1960-1997) salinity (b) and temperature (c). (d) is the temperature difference between the mean over 1980-1997 and the mean over 1960-1975 as a function of longitude and depth along the equator. Shading is for positive and contour interval is $0.2^{\circ} \mathrm{C}$.

[6] A change in stratification between the two epochs is associated with fluctuations in the baroclinic modes characteristics. The contribution of the first three baroclinic modes to the zonal current anomalies before and after the late 1970s is compared in Figure 2. Figure 2 shows the root mean square variance (hereafter, rms) of surface zonal current anomalies from the contribution of the first three modes during periods of 1960-1975 (a-c) and 1980$1997(\mathrm{~d}-\mathrm{f})$. Note that the anomaly is defined as the deviation from the mean over the entire period (19501997). Figures $2 \mathrm{~g}-2 \mathrm{i}$ are the difference of rms between the two epochs.

[7] Larger values for zonal current variance are confined within $5^{\circ} \mathrm{N}-5^{\circ} \mathrm{S}$ during the two epochs. For mode 1 , maximum variance is centered in the western and central equatorial Pacific, whereas the contribution of the second baroclinic mode is more important in the eastern equatorial Pacific [Dewitte et al., 1999]. The third mode presents variance peaks in the far eastern equatorial Pacific reaching $8 \mathrm{~cm} \mathrm{~s}^{-1} \sim 10 \mathrm{~cm} \mathrm{~s}^{-1}$ (Figures $2 \mathrm{c}$ and $2 \mathrm{f}$ ), i.e., $\sim 70 \%$ of the mode 1 variance peak along the equator.

[8] After the late 1970s, the contribution for the second and the third baroclinic mode significantly increases in the central equatorial Pacific (Figures $2 \mathrm{~h}$ and $2 \mathrm{i}$ ) where the zonal wind stress anomaly has maximum rms (Figure $2 \mathrm{j}$ ). We found similar results in terms of meridional currents and sea level pressures with significant increase in the central equatorial Pacific (not shown). It indicates that local forcing of Kelvin and Rossby waves for the higher baroclinic modes is reinforced after the late 1970s. The higher-order modes Rossby waves with a slower gravity wave speed are associated with an increase of ENSO oscillation period according to the ocean wave dynamics [Philander et al., 1984]. The frequency spectrum of NINO3 $\left(5^{\circ} \mathrm{N}-5^{\circ} \mathrm{S}\right.$, $\left.210^{\circ} \mathrm{E}-270^{\circ} \mathrm{E}\right) \mathrm{SSTA}$ for SODA also indicates that longer periods are favored after the late 1970s (see Figure 4b). These results suggest that an increase of ENSO period oscillation after the late 1970s is associated with the variability of the higher baroclinic modes.

[9] In order to check this hypothesis, we analyze the projection of the wind stress onto the baroclinic mode. Based on mixed layer dynamics [Cane, 1984], a body force of magnitude is $\tau_{n}(x, y, t)=\tau(x, y, 0, t) \frac{A_{n}(0)}{D}$, where $D$ is the depth of the ocean and $A_{n}(z)$ is the vertical structure function. Obviously, this indicates that the wind stress acting on each baroclinic mode depends on the surface amplitude of vertical structure function, i.e., $A_{n}(0)$. Figures $3 \mathrm{a}-3 \mathrm{c}$ show the difference of rms for $A_{n}(0)(n=$ 1, 2, 3) between 1960-1975 and 1980-1997 along the equator. Figures $3 \mathrm{a}-3 \mathrm{c}$ indicate that the rms of $A_{n}(0)$ for the second mode significantly increases in the central equatorial Pacific after the late 1970s. For the third mode an increase of the rms of $A_{n}(0)$ is significant in the central and eastern equatorial Pacific. It is worth to note that the effect of an increase of surface amplitude $A_{n}(0)$ in the central equatorial Pacific may be significant in a coupled system because there is large wind stress forcing (Figure 2j). This result suggests that the atmospheric forcing for the higher baroclinic modes is increased in the central and eastern equatorial Pacific after
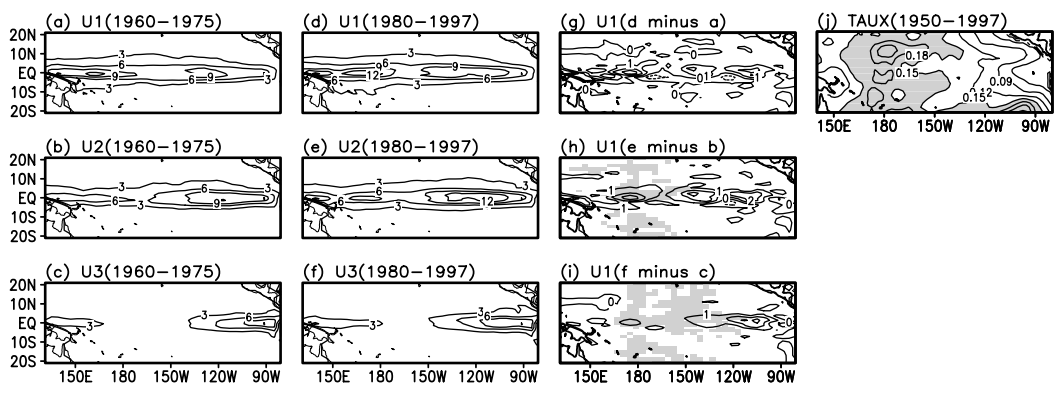

Figure 2. The rms variance of surface zonal currents for the contribution (a) of the first mode, (b) the second mode and (c) the third mode for the period of 1960-1975. (d)-(f) is the same as in (a)-(c) except for the period of 1980-1997. Units are $\mathrm{cm} \mathrm{s}^{-1}$ and contour intervals are every $3 \mathrm{~cm} \mathrm{~s}^{-1}$. (g)-(i) are the difference of rms variance between the two periods ((d)-(f) minus (a)-(c)). The shading indicates regions for which the rms variance increases above the $95 \%$ confidence level. Contour intervals are $1 \mathrm{~cm} \mathrm{~s}^{-1}$. The rms variance of zonal wind stress anomalies for the period of $1950-1997$ is displayed (2j). Units are dyn $\mathrm{cm}^{-2}$ and shading is above $0.15 \mathrm{dyn}^{\mathrm{cm}} \mathrm{cm}^{-2}$. 

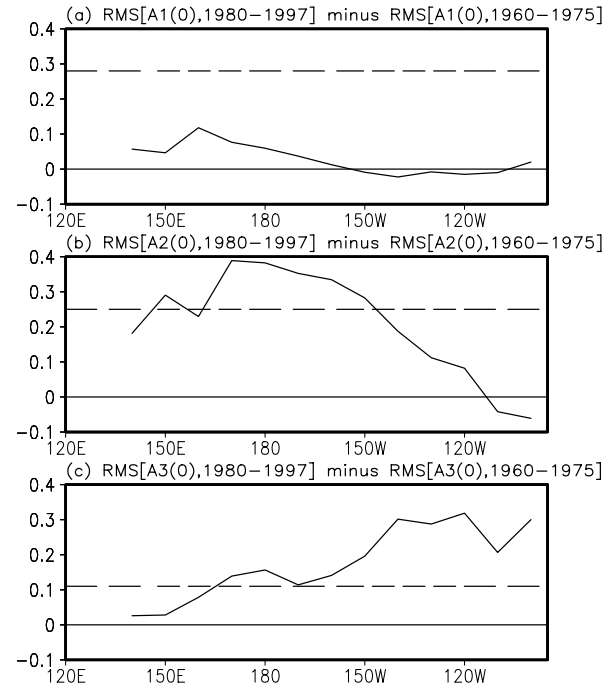

Figure 3. Difference of rms variance for $A_{n}(0)$ along the equator of (a) the first mode, (b) the second mode and (c) the third mode between 1960-1975 and 1980-1997. Unit is nondimensional. The horizontal dashed line indicates the $95 \%$ confidence level for rms variance increase.

the late 1970s, namely that higher-order baroclinic modes are favored after the late 1970s.

\section{Simple Model Experiments}

[10] In this section, we test the impact of changes in the energey distribution on the baroclinic modes in a simple coupled model based on the above results. We use a simple coupled model similar to the one of Yeh et al. [2001]. The atmospheric model is a statistical model based on the singular value decomposition (SVD) of SSTAs and wind stress anomalies from SODA for the period 1950-1997. The ocean model is an extension of the Cane and Zebiak [1987] model including three vertical baroclinic modes. The values for phase speed $\left(C_{n}\right)$ and projection coefficient $\left(P_{n}\right)$ before and after the late 1970s are derived from the vertical mode decomposition of a mean density profile along the equator (Table 1). As expected, the averaged values of $P_{n}$ in the central equatorial Pacific increase for higher baroclinic modes after the late 1970 s (increase of $19 \%$ and $25 \%$ for mode 2 and 3 , respectively) indicating that atmospheric forcing projects more onto the higher-order baroclinic modes. The change for phase speed between the two epochs is however very small [cf. Dewitte, 2000].

Table 1. Parameter Values for the Ocean Model

\begin{tabular}{|c|c|c|c|c|c|c|}
\hline & \multicolumn{3}{|c|}{$1960-1975$ (Exp1) } & \multicolumn{3}{|c|}{$1980-1997(\operatorname{Exp} 2)$} \\
\hline & $\mathrm{n}=1$ & $\mathrm{n}=2$ & $\mathrm{n}=3$ & $\mathrm{n}=1$ & $\mathrm{n}=2$ & $\mathrm{n}=3$ \\
\hline $\begin{array}{l}\text { Phase } \\
\quad \text { speed }(\mathrm{m} / \mathrm{s}) \text { : } \\
C_{n}\end{array}$ & 2.69 & 1.61 & 0.98 & 2.65 & 1.61 & 0.99 \\
\hline $\begin{array}{l}\text { Projection } \\
\text { coefficient } \\
P_{n}=\frac{150}{\int_{-H}^{0} A_{n}^{2}(z) d z}\end{array}$ & 0.65 & 0.39 & 0.12 & 0.66 & 0.48 & 0.16 \\
\hline
\end{tabular}

These values are derived along the equator $\left(0^{\circ} \mathrm{N}, 160^{\circ} \mathrm{E}-220^{\circ} \mathrm{E}\right)$.

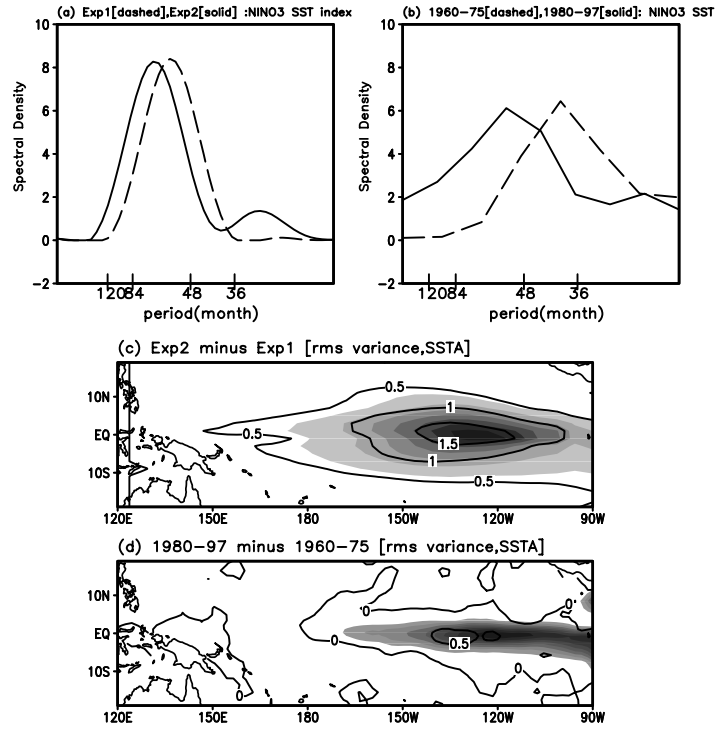

Figure 4. The normalized power spectrum of the simulated NINO3 SST index for Exp1 (dashed) and Exp2 (solid) (a). (b) is the same as in (a) except for SODA SSTA during the period of 1960-1975 (dashed) and 1980-1997 (solid). (c) is the difference of rms variance for simulated SSTA (Exp2 minus Exp1). (d) is the same as in (c) except for SODA SSTA (1980-1997 minus 1960-1975). Shading indicates regions in which the rms variance increases above $95 \%$ confidence level. Contour interval is $0.5^{\circ} \mathrm{C}$.

[11] Two simulations (Exp1 and Exp2) are performed over a 300 year period to show the impact of the observed changes in baroclinic mode energy distribution in the late 1970s. Exp2 is identical to Exp1 except for the value of $C_{n}$ and $P_{n}$ taken before (Exp1) and after (Exp2) the late 1970s. Figure 4a shows the power spectrum of the NINO3 SST index for Exp1 (dashed) and Exp2 (solid). The dominant period of NINO3 SST index for Exp1 and Exp2 is $4.5 \mathrm{yr}$ and 6yr, respectively. Although the difference in the dominant period between the two experiments is not as large as in the observations (Figure 4b), the realistic magnitude of the shift in period peaks for the model suggests that the change in the relative contribution of the baroclinic modes is associated with an increase of ENSO oscillation period.

[12] Figure $4 c$ is the difference of rms (Exp2 minus Exp1) for simulated SSTA. We have also displayed the difference in rms between the two epochs for the SODA SSTAs (Figure 4d). The rms for Exp2 significantly increases in the central and eastern tropical Pacific, which is associated with the increase of ENSO amplitude after the late 1970s. The patterns are comparable, consistent with a Kelvin wave response: the projection coefficient being amplified for the higher order modes for the model (observations) in Exp 2 (after the late 1970s), the forced Kelvin wave for the highorder modes with a slower phase speed than the gravest mode is favored in the eastern Pacific. Note also that the meridional scale of variability for the observations is rather small $\sim 200 \mathrm{~km}$ at $130^{\circ} \mathrm{W}$ indicative of a response in SSTAs to higher-order baroclinic mode Kelvin wave forcing.

[13] In order to test the robustness of our result, in particular with regards to the definition of the atmospheric model, we repeated experiments similar to Exp1 and Exp2 
except that the atmospheric modes of the statistical model are computed over the two different periods under concerns (1960-1975 and 1980-1997) from the SODA SSTAs and wind stress anomalies. Thus Exp1 and Exp2 are repeated with the new two different atmospheric models. When the relative contribution of the forced higher baroclinic modes increases, in both cases, the model also exhibits a comparable increase of the amplitude and period of ENSO oscillation (not shown). Again, it suggests that an increase in the higher-order baroclinic modes contribution in a parameter range characteristics of the Pacific climate shift of the 1970s is associated with larger amplitude and longer period of ENSO oscillation.

[14] It is noteworthy that we found that there are differences in the atmospheric SVD modes before and after the 1970s. According to Yeh et al. [2001], these modifications have the potential to modify the characteristics of the ENSO variability. However, we hypothesize that these modifications in the atmospheric modes are a response to a change in the ocean.

\section{Concluding Remarks}

[15] We investigated the change in the baroclinic mode contributions at low frequency. Our analysis suggests that the vertical stratification substantially increases at upper levels in the tropical Pacific after the late 1970s, which is mostly due to vertical structural changes in the temperatures within the thermocline.

[16] The change of vertical stratification is associated with an increase of the contributions for the higher baroclinic modes to the current and pressure anomalies. After the late 1970s, the contribution for the second and the third baroclinic mode significantly increases in the central equatorial Pacific, suggesting that local forcing of Kelvin and Rossby waves for the higher baroclinic modes is reinforced [Dewitte, 2000; Shu and Clarke, 2002]. The variance analysis of surface amplitude $A_{n}(0)$ supports this hypothesis, of more intense atmospheric forcing for the higher baroclinic modes after the late 1970s.

[17] Because the SODA system is based on a data assimilation system forced by winds, there is the possibility that decadal variations of wind forcing are responsible for the EDV [Karspeck and Cane, 2002; Pierce et al., 2000; Wang and An, 2001]. If this is the case, our study indicates that such decadal wind forcing signal will project preferentially onto the equatorial higher-order baroclinic mode. There is, however, no particular reason for the wind forcing at such time scales to favor one mode over another, which suggest that the changes in stratification impacting on the wave dynamics are more likely to be due to oceanic extratropical connections and that decadal changes in the wind stress forcing are the result of a coupled response to the ocean. Thus our study suggests that the decadal signal associated with the climate shift of the late 1970s is linked to the change in the ENSO period and magnitude resulting from changes in the tropical coupled mode characteristics, themselves associated to modification of the energy distribution on the baroclinic modes.

[18] Coupled climate models suggest that under climate change, the stratification of the equatorial Pacific ocean increase [Timmermann et al., 1999; Cai and Whetton,
2000]. This takes place in associated with an increase in thermocline depth, which tends to suppress the contribution of the high-order modes. Consequently, we can not exclude the possibility that despite of increased stratification it does not always translate into increased period and amplitude of ENSO events. For example, Timmerman et al. [1999] argued that the response of ENSO to greenhouse warming in a coupled model generally does not show increased period or amplitude despite in presence of increased stratification. This is currently being investigated from a general circulation coupled model that includes all the different processes invoked in this study.

[19] Acknowledgments. This work was supported by the Korean Government's BK21 Project. Also it was partly supported by grants from the National Science Foundation ATM-9814295 and ATM-0122859, the National Oceanic and Atmospheric Administration NA16-GP2248 and National Aeronautics and Space Administration NAG5-11656.

\section{References}

Cai, W., and P. H. Whetton (2000), Evidence for a time-varying pattern of greenhouse warming in the Pacific Ocean, Geophys. Res. Lett., 27(16), $2577-2580$.

Cane, M. A. (1984), Modeling sea level during El Nino, J. Phys. Oceanogr. 14, $1864-1874$.

Cane, M. A., and S. E. Zebiak (1987), Prediction of El Nino events using a physical model. Atmosphere and Ocean Variability, H. Cattel, Ed. R. Meteorol. Soc., 153-182.

Carton, et al. (2000), A simple ocean data assimilation analysis of the global upper ocean 1950-95. Part I: Methodology, J. Phys. Oceanogr., 30, 294-309

Dewitte, B. (2000), Sensitivity of an intermediate ocean-atmosphere coupled model of the tropical Pacific to its oceanic vertical structure, J. Clim., 13, 2363-2388.

Dewitte, B., et al. (1999), Vertical structure of an OGCM forced simulation of the tropical Pacific in 1985-1994, J. Phys. Oceanogr., 29, $1542-$ 1570 .

Karspeck, A. R., and M. A. Cane (2002), Tropical Pacific 1976-77 climate shift in a Linear, wind-driven model, J. Phys. Oceanogr. $32,2350-2360$

Kessler, W. S., and J. P. McCreary (1993), The annual wind-driven Rossby wave in the subthermocline equatorial Pacific, J. Phys. Oceanogr., 23, $1192-1207$

Knutson, X., and S. Manabe (1998), Model assessment of decadal variability and trends in the tropical Pacific ocean, J. Clim., 11, 2273-2296.

Pacanowski, et al. (1993), The GFDL modular ocean model users guide version 1, GFDL Ocean Group Tech. Rep. No. 2, 77 pp.

Philander, et al. (1984), Unstable air-sea interactions in the tropics, J. Atmos. Sci., 41, 604-613.

Pierce, et al. (2000), Connections between the Pacific ocean tropics and midlatitudes on decadal timescales, J. Clim., 13, 1173-1194.

Shu, L., and A. J. Clarke (2002), Using an ocean model to examine ENSO dynamics, J. Phys. Oceanogr., 32, 903-923.

Timmermann, et al. (1999), Increased El Nino frequency in a climate model forced by future greenhouse warming, Nature, 398, 694-697.

Wang, B., and S.-I. An (2001), Why the properties of El Nino changed during the late 1970s, Geophys. Res. Lett., 28(19), 3709-3712.

Wang, B., and Y. Wang (1996), Temporal structure of the Southern Oscillation as revealed by waveform and wavelet analysis, J. Clim., 9, 15861598 .

Yeh, et al. (2001), The characteristic oscillation induced by coupled processes between oceanic vertical modes and atmospheric modes in the tropical Pacific, Geophys. Res. Lett., 28(14), 2847-2850.

Zhang, et al. (1998), Origin of warming and El Nino change on decadal scales in the tropical Pacific Ocean, Nature, 391, 879-883.

B.-K. Moon, J.-G. Jhun, and I.-S. Kang, School of Earth and Environmental Sciences, Seoul National University, Seoul 151-747, Korea. S.-W. Yeh and B. P. Kirtman, Center for Ocean-Land-Atmosphere Studies, 4041 Powder Mill Road, Suite 302, Calverton, MD 20705, USA. (swyeh@cola.iges.org)

B. Dewitte, Laboratoire d'Etude en Géophysique et Océanographie Spatiale, IRD, Anse Vata BP A5-98848 NOUMEA Cedex, New Calédonia, France. 